\title{
PENGARUH AKTIVITAS MELIHAT DEKAT TERHADAP TAJAM PENGLIHATAN PADA MURID SEKOLAH MENENGAH PERTAMA DI KECAMATAN JATINANGOR
}

\begin{abstract}
Raisha Pratiwi Indrawati $^{1}$, Reni Farenia ${ }^{2}$, Mayasari Wahyu Kuntorini ${ }^{3}$
${ }^{1}$ Fakultas Kedokteran, Universitas Padjadjaran, Bandung, Indonesia, ${ }^{2}$ Divisi Fisilogi, Fakultas Kedokteran, Universitas Padjadjaran, Bandung, Indonesia ${ }^{3}$ Departemen Ilmu Kesehatan Mata, Pusat Mata Nasional, Rumah Sakit Mata Cicendo, Bandung, Indonesia

Abstract

Near work activity was estimates as risk factor of refractive error. This study aimed to analyze the association between near work activity and visucal acuity in junior high school students in Jatinangor. This study used cross-sectional method. Total of 147 subjects were screened for visual impairment and assessed for near work activities. Result showed total diopter-hours and time spent for each near work activity was less in group with visual acuity $\geq 6 / 18$ than $<6 / 18$ with no significant difference, except for playing games $(p=0.018)$. In conclusion, near work activity does not have impact on visual acuity, except for playing games.
\end{abstract}

Keywords: junior high school students, near work activity, visual acuity

Korespondensi: Redaksi JIFO, Laboratorium Sentral, Universitas Padjadjaran, Jalan Raya Jatinangor KM. 21, Sumedang, Jawa Barat, Indonesia. E-mail: amrosdianto@gmail.com 


\section{PENDAHULUAN}

Gangguan mata di seluruh dunia masih banyak terjadi. World Health Organization (WHO) mengestimasi pada tahun 2006 kurang lebih terdapat 314 juta orang di seluruh dunia mengalami gangguan visual termasuk akibat gangguan refraksi. Gangguan refraksi ini terjadi di berbagai usia dan etnis. Sedikitnya 143 juta anak berusia 5 - 15 tahun dan 45 juta orang dewasa berusia kerja ( 16 - 45 tahun) mengalami gangguan refraksi tersebut. ${ }^{1,2} \mathrm{Di}$ Indonesia, ganggaun refraksi merupakan penyebab kebutaan ke-3 setelah katarak dan glaukoma. ${ }^{3}$ Beberapa penelitian mengenai gangguan refraksi menunjukkan gangguan refraksi menjadi masalah utama kesehatan masyarakan pada anak usia sekolah. ${ }^{4,5}$

Untuk meningkatkan upaya preventif dalam menurunkan angka gangguan refraksi tersebut, maka diperlukan pengetahuan mengenai faktor-faktor yang mungkin memengaruhi gangguan refraksi, sehingga intervensi yang efektif dapat

\section{METODE}

Penelitian ini dilakukan dengan mengunakan metode analitik dengan pendekatan potong-lintang. Data diambil dengan melakukan pemeriksaan tajam penglihatan jauh dan pengisian kuesioner mengenai kebiasaan melakukan aktivitas melihat dekat. Pengambilan data dan penelitian dilakukan di SMP di Kecamatan Jatinangor pada bulan Mei - November 2013.

Sampel pada penelitian ini adalah murid kelas VII, VIII, dan IX SMP di Kecamatan Jatinangor yang dipilih dengan cara multistage random sampling, sampel diambil secara acak dari tiap kelas pada sekolah yang terpilih. Kriteria inklusi subjek penelitian ini adlaah murid kelas VII, VIII, dan IX SMP di Kecamatan diimplementasikan. Meskipun proporsi gangguan refraksi seperti miopia diduga dipengaruhi faktor genetik, belum ada bukti yang memperlihatkan kontribusi faktor genetik terhadap miopia ringan dan sedang. ${ }^{6}$ Dengan demikian, selain mempertimbangkan faktor genetik, faktor lain seperti faktor lingkungan dapat dipertimbangkan sebagai faktor ynag dapat diintervensi untuk mencegah gangguan visual. Salah satu faktor lingkungan tersebut adalah aktivitas melihat dekat. ${ }^{6,7}$ Dalam melihat dekat, kontraksi otot siliaris yang terus menerus selama proses akomodasi dapat menurunkan tajam penglihatan. ${ }^{6-9}$

Data mengenai gangguan refraksi di Jatinangor masih sedikit, serta diperlukan analisis mengenai faktor risiko dari gangguan refraksi tersebut agar tindakan preventif dapat dilakukan sedini mungkin, maka penulis melakukan penelitian yang bertujuan untuk menganalisis hubungan aktivitas melihat dekat dengan tajam penglihatan pada murid sekolah menengah pertama di Kecamatan Jatinangor.

Jatinangor yang berusia $\leq 15$ tahun dan bersedia mengikuti penelitian. Kriteria eksklusi pada penelitian ini adalah murid yang memiliki kelainan mata organik, tidak mengisi kuesioner dengan sesuai, atau informasi yang didapatkan tidak lengkap.

Pada penelitian ini tingkat kemaknaan $(\alpha)=0,05$ dan eror tipe II $(\beta)=0,2$, dengan sampel minimum 46 pada masing-masing kelompok atau 92 untuk kedua kelompok.

Tajam penglihatan diukur menggunakan $R A A B$ chart. Skala pengukuran adalah kategorik. Tajam penglihatan dikategorikan baik bila tajam penglihatan $6 / 18$ atau lebih, sedangkan tajam penglihatan dikategorikan kurang bila tajam 
penglihatan dikategorikan kurang bila tajam penglihatan kurang dari 6/18.

Data yang diambil baik dari kuesioner maupun daripemeriksaan tajam penglihatan akan dimasukkan dan dikoding secra komputerisasi menggunakan program Microsoft Excel, kemudian dianalisis menggunakan

\section{HASIL}

Penelitian ini menggunakan data primer yang diperoleh dari pemeriksaan langsung tajam penglihatan dan wawancara kuesioner aktivitas melihat dekat. Penelitian ini dilakukan terhadap tiga SMP yang terpiih untuk mewakili SMP di Jatinangor, terdiri dari satu SMP negeri yaitu SMPN 2 Jatinangor dan dua SMP swasta yaitu SMP Imam Bukhori Jatinnagor dan SMP Darul Fatwa Jatinangor. Data yang terkumpul dari penelitian ini berjumlah 143 sampel.

Subjek merupakan siswa kelas VII, VIII, dan IX dari masing-masing program SPSS 15.0. Setelah data tersedia, selanjutnya dilakukan uji normalitas data. Data yang terdistribusi normal akan dianalisis menggunakan uji-T tidak berpasangan dan jika data tidak terdistribusi normal akan dianalisis menggunakan uji MannWhitney.

sekolah. Karakteristik sebaran dari 143 subjek dapat dilihat pada tabel 1. Dari hasil pengukuran tahamn penglihatan dengan menggunakan $R A A B$ Tumbling E-chart, subjek dibagi ke dalam dua kategori, yaitu kategori tajam penglihatan baik $(\geq 6 / 18)$ sebanyak 96 orang dan kategori tajam penglihatan kurang $(<6 / 18)$ sebanyak 47 orang. Tidak terdapat berdaan bermakna antara tajam penglihatan laki-laki dan perempuan.

Tabel 1. Karakteristik subjek.

\begin{tabular}{lcccc}
\hline Variabel & $\begin{array}{c}\text { Frekuensi } \\
(\mathbf{n})\end{array}$ & $\begin{array}{c}\text { Tajam Penglihatan } \\
\mathbf{\mathbf { 6 } / \mathbf { 1 8 }}\end{array}$ & $\begin{array}{c}\text { Tajam Penglihatan } \\
<\mathbf{6 / 1 8}\end{array}$ & Nilai p \\
\hline Gender & & & & \\
$\quad$ Laki-laki & $56(39,2 \%)$ & $36(64,3 \%)$ & $20(35,7 \%)$ & 0,561 \\
$\quad$ Perempuan & $87(60,8 \%)$ & $60(69 \%)$ & $27(31,0 \%)$ & \\
Usia & & & & \\
11 & $1(0,7 \%)$ & 1 & 0 & \\
12 & $22(15,4 \%)$ & 18 & 4 & 1,072 \\
13 & $44(30,8 \%)$ & 32 & 12 & \\
14 & $45(31,5 \%)$ & 27 & 18 & \\
15 & $31(21,7 \%)$ & 18 & 13 & \\
Total & $\mathbf{1 4 3}(\mathbf{1 0 0 \% )}$ & $\mathbf{9 6}$ & $\mathbf{4 7}$ & \\
\hline
\end{tabular}

Tabel 2. Gambaran durasi aktivitas melihat dekat.

\begin{tabular}{lcccc}
\hline \multirow{2}{*}{ Variabel } & \multicolumn{3}{c}{ Durasi (jam/minggu) } & \multirow{2}{*}{ Nilai p } \\
\cline { 2 - 4 } & $16(2,5-47,5)$ & $15,83(2,5-47,5)$ & $19(2,5-37,5)$ & 0,007 \\
Membaca & $16(0-39)$ & $14(0-39)$ & $16(0-36)$ & 0,088 \\
Menonton TV & $7(0-25)$ & $7(0-25)$ & $7(0-23)$ & 0,967 \\
Menggunakan komputer & $7(0-25)$ & $9(0-25)$ & $7(0-25)$ & 0,195 \\
Bermain games & $101,91 \pm 37,37$ & $95,69 \pm 38,84$ & $105,92 \pm 36,05$ & 0,110 \\
Aktivitas melihat dekat & & & & \\
(diopter hours) & &
\end{tabular}


Tabel 3. Durasi aktivitas melihat dekat berdasarkan tajam penglihatan.

\begin{tabular}{|c|c|c|c|}
\hline \multirow[b]{2}{*}{ Aktivitas } & \multicolumn{2}{|c|}{ Durasi (jam/minggu) } & \multirow[b]{2}{*}{ Nilai $\mathbf{p}$} \\
\hline & $\begin{array}{c}\text { Tajam Penglihatan } \\
\geq 6 / 18\end{array}$ & $\begin{array}{c}\text { Tajam Penglihatan } \\
<6 / 18\end{array}$ & \\
\hline Membaca & $16,45(2,5-37)$ & $15,5(3,5-47,5)$ & $0,689 *$ \\
\hline Menonton TV & $16(0-39)$ & $15(0-30)$ & $0,120 *$ \\
\hline Menggunakan komputer & $7,25(0-25)$ & $7(0-24)$ & $0,326^{*}$ \\
\hline Bermain games & $9(0-25)$ & $6,5(0-24)$ & $0,018 *$ \\
\hline $\begin{array}{l}\text { Aktivitas melihat dekat } \\
\text { (diopter hours) }\end{array}$ & $104,05 \pm 35,88$ & $95,53 \pm 40,28$ & $0,329 * *$ \\
\hline
\end{tabular}

Dari hasil pengisian kuesioner mengenai aktivitas melihat dekat, subjek memiliki kiebiasaan melakukan aktivitas melihat dekat dengan durasi yang bervariasi, seperti yang disajikan dalam tabel 2. Berdasarkan tabel tersebut, rerata diopter hours aktivitas melihat dekat adalah 101,91 $\pm 37,37$ jam/minggu, dengan aktivitas yang paling lama dilakukan adalah membaca, baik untuk belajar maupun untuk hiburan $(16,0(2,5-47,5) \mathrm{jam} / \mathrm{minggu})$. Secara umum, anak perempuan melakukan aktivitas melihat dekat dengan durasi yang lebih lama dari anak laki-laki, kecuali dalam bermain games. Secara statistik durasi aktivitas melihat dekat antara laki-laki dan perempuan tidak memperlihatkan perbedaan yang signifikan, kecuali pada aktivitas membaca yaitu perempuan lebih banyak membaca secara signifikan daripada laki-laki $(\mathrm{p}=0,007)$.

Tabel 3 menunjukkan perbandingan kedua kelompok tajam penglihatan. Total diopter hours aktivitas melihat dekat lebih lama dilakukan oleh kelompok dengan tajam penglihatan baik $(104,5 \pm 35,88$

\section{PEMBAHASAN}

Pada penelitian ini, durasi total aktivitas melihat dekat terbukti tidak berhubungan secara signifikan dengan gangguan refraksi, kelompok dengan tajam penglihatan baik dan kelompok dengan tajam penglihatan kurang jam/minggu) dibandingkan dengan kelompok dengan tajam penglihatan kurang (95,53 \pm 40,28 jam/minggu). Meskipun demikian, tidak ada perbedaan yang bermakna antara diopter hours aktivitas melihat dekat pada kelompok dengan tajam penglihatan baik dibandingkan dengan kelompok tajam penglihatan kurang $(\mathrm{p}=0,329)$.

Begitupun dengan durasi masingmasing aktivitas, kelompok dengan tajam penglihatan baik menghabiskan waktu lebih lama pada aktivitas baca $(16,45 \quad(2,5-37,0) \quad$ jam/minggu $)$, menonton televisi $(16,00 \quad(0-39,0)$ jam/minggu), menggunakan komputer $(7,25 \quad(0-25,0) \quad \mathrm{jam} / \mathrm{minggu})$, dan bermian games $(9,00 \quad(0-25,0)$ jam/minggu) dibandingkan kelompok dengan tajam penglihatan kurang. Sama halnya seperti pada diopter hours aktivitas melihat dekat, perbedaan durasi masing-masing aktivitas melihat dekat antara kedua kelompok dianggap tidak bermakna ( $p>0,05)$, kecuali pada durasi bermain games yang memperlihatkan perbedaan yang signifikan $(\mathrm{p}=0,018)$.

memiliki rerata durasi aktivitas melihat dekat yang tidak jauh berbeda. Hasil ini sejalan dengan penelitian serupa oleh $\mathrm{Lu}$ et al dan Ip et al di China dan Sydney. Anak yang mengalami miopia tidak terbukti melakukan aktivitas 
melihat dekat dengan durasi lebih lama. ${ }^{6,10}$ Penelitian lain di Singapura membuktikan bahwa membaca buku tidak berhubungan dengan kejadian miopia, yang bertentangan dengan penelitian potong lintang sebelumnya yang menunjukkan bahwa sebagian besar anak yang membaca mengalami miopia. $^{11,12}$ Hasil tersebut berbeda dnegan sebuah penelitian di Singapura dan India yang menunjukkan bahwa anak yang melakukan aktivitas melihat dekat seperti membaca, menggunakan komputer, dan menonton televisi lebih banyak berisiko mengalami gangguan refraksi. ${ }^{13,14}$ Perbedaan hasil tersbeut kemungkinan disebabkan adanya pengaruh faktor-faktor lain yang tidak dipertimbangkan baik faktor kebiasaan melihat dekat seperti kontinuitas membaca, maupun faktor lingkungan seperti pencahayaan, jenis buku yang dibaca, termasuk faktor genetik. Selain itu, terdapat perbedaan rentang usia antara subjek pada penelitian ini (11-15 tahun) dengan penelitian sebelumnya di Singapura (7-9 tahun). ${ }^{14}$ Hubungan antara membaca dan miopia diduga lebih kuat pada subjek yang berusia lebih muda yang masih mengalami masa perkembangan penglihatan, dibandingkan subjek yang berusia lebih tua. $^{12}$

Penelitian ini juga menunjukkan bawa durasi bermian games memiliki pengaruh yang signifikan terhadap tajam penglihatan. Kelompok dengan tajam penglihatan yang lebih baik memiliki durasi bermain games yang lebih lama. Hasil ini berkeblaikan

\section{SIMPULAN}

Berdasarkan hasil penelitian dan pembahasan, dapat disimpulkan bahwa aktivitas melihat dekat berhubungan dengan beberapa penelitian sebleumnya yang menunjukkan tidak adanya pengaruh durasi bermain games terhadap tajam penglihatan, ${ }^{15}$ namun sejalan dengan penelitian Lu et al yang menunjukkan durasi bermain games yang lebih singkat pada anak miopia. ${ }^{10}$ Penelitian lain oleh Ip et al menunjukkan bahwa bermain games berhubungan dengan kondisi hiperopia, meskipun tidak dapat dikatakan bahwa bermain games memiliki pengaruh protektif terhadap perkembangan miopia. ${ }^{12}$ Pada penelitian ini, beberapa subjek bermain games pada gadget, seperti telepon genggam, dalam frekuensi yang sering namun durasi yang sebentar. Hal ini mungkin dapat menjelaskan mengapa kelompok dengan tajam penglihatan baik memiliki durasi bermain games yang lebih lama tanpa memiliki gangguan visual, karena mereka tidak melakukan aktivitas tersebut secara kontinu. Kontinuitas melakukan aktivitas dekat diduga merupakan faktor yang signifikan terhadap terjadinya miopia. ${ }^{7}$

Keterbatasan penelitian ini adalah penggunaan $R A A B$ tumbling E-chart sehingga hanya dapat mengetahui taham penglihatan lebih atau kurang dari 6/18, tidak dapat mengetahui tajam penglihatan sesungguhnya. Selain itu, tidak dilakukan penelusuran faktorfaktor lain yang dapat memengaruhi kualitas melihat dekat, seperti pencahayaan ruangan, ukuran media, dan posisi saat melakukan aktivitas dekat.

dengan aktivitas bermain games, namun tidak berhubungan dengan aktivitas melihat dekat lainnya.

\section{PENDANAAN}

Penelitian ini tidak didanai oleh sumber hibah manapun

\section{KONFLIK KEPENTINGAN}

Tidak ada potensi konflik kepentingan. 


\section{DAFTAR PUSTAKA}

1. Thylefors B. A global initiative for th elimination of avoidable blindness. International Centre for Eye Healtth; 2007. Hlm. 2-17.

2. Resnikoff S, Pascolini D, Mariotti SP, Pokharel GP. Global magnitude of visual impairment caused by uncorrected refractive errors in 2004. SciELO Public health; 2008. Hlm. 63-70.

3. Kementerian Kesehatan Republik Indonesia. Gangguan penglihan masih menjadi masalah kesehatan. Pusat Komunikasi Publik Sekreterian Jenderal Kementerian Kesehatan RI; 2010. Tersedia dari: www.depkes.go.id/index.php/berit a/press-release/845-gangguanpenglihatan-masih-menjadimasalah-kesehatan.pdf.

4. Dandona R, Dandona L, Srinivas M, Sahare P, Narsaiah S, Munoz $\mathrm{SR}$, et al. Refractive error in children in a rural population in India. ARVO; 2002. Hlm. 615-22.

5. Murthy G, Gupta SK, Ellwein LB, Munoz SR, Pokharel GP, Sanga L, et al. Refractive error in children in an urban population in New Delhi. Investigative Ophtalmology \& Visual Science 2002; 43(3):62331.

6. Ip JM, et al. Ethnic differences in the impact of parentalk myopia: Findings from a population-based study of 12-years-old Australian children.

Investigative

Ophtalmology \& Visual Science 4. 2007;48(6):2520-8.

7. Ip JM, Saw SM, Rose KA, Morgan IG, Kifley A, Wang JJ, et al. Role of near work inmyopia: Findings in a sample of Australian school children. ARVO;2008. HIm. 290310.

8. Pan C-W, Ramamurthy D, Saw SM. Worldwide prevalence and risk factors for myopia. Ophtalmic and Physiological Optics. 2012;32(1):3-16.

9. Vaughan, Asbury, editor. General ophthalmology. Edisi ke-17. McGraw Hill Lange; 2007.

10. Lu B, Congdon N, Liu X, Choi K, Lam DS, Zhang $M$, et al. Associations between near work outdoor activity, and myopia among adolescent students in rural China: The Xichang pediatric refractive error study report no.2. Archives of Ophtalmology. 2009;127(6):769.

11. Saw SM, Shankar A, Tan SB, Taylor H, Tan DT, Stone RA, et al. A cohort study on incident myopia in Singaporean children, Investigative ophthalmology \& Visual Science. 2006;47(5):183944.

12. Saw SM, Chua WH, Hong CY, Wu HM, Chan WY, Chia KS, et al. Nearwork in early-onset myopia. Investigative Ophthalmology \& Visual Science. 2002;43(2):332-9.

13. Prema N. Causing factors of refractive error in children: Heredity or environment? Indian Journal of Science and Technology. 2011:1773-4.

14. Saw SM, Tong L, Chua WH, Chia KS, Koh D, Tan DT, et al. Incidence and progression of myopia in Singaporean school children. Investigative 
ophthalmology \& Visual Science.

2005;46(1):51-7.

15. Liang CL, Yen E, Su JY, Liu C, Investigative Ophthalmology \& Chang TY, Park N, et al. Impact of Visual Science. 2004;45(10):3446family history of high myopia on 52.

level and onset of myopia, 